\title{
De novo assembly of red clover transcriptome based on RNA-Seq data provides insight into drought response, gene discovery and marker identification
}

Steven A Yates ${ }^{1,3}$, Martin T Swain², Matthew J Hegarty ${ }^{1}$, Igor Chernukin ${ }^{3}$, Matthew Lowe ${ }^{1}$, Gordon G Allison ${ }^{1}$, Tom Ruttink ${ }^{4}$, Michael T Abberton ${ }^{1,5}$, Glyn Jenkins $^{2}$ and Leif Skøt ${ }^{{ }^{*}}$

\begin{abstract}
Background: Red clover (Trifolium pratense L.) is a versatile forage crop legume, which can tolerate a variety of soils and is suitable for silage production for winter feed and for grazing. It is one of the most important forage legumes in temperate livestock agriculture. Its beneficial attributes include ability to fix nitrogen, improve soil and provide protein rich animal feed. It is however, a short-lived perennial providing good biomass yield for two or three years. Improved persistency is thus a major breeding target. Better water-stress tolerance is one of the key factors influencing persistency, but little is known about how red clover tolerates water stress.

Results: Plants from a full sib mapping family were used in a drought experiment, in which the growth rate and relative water content (RWC) identified two pools of ten plants contrasting in their tolerance to drought. Key metabolites were measured and RNA-Seq analysis was carried out on four bulked samples: the two pools sampled before and after drought. Massively parallel sequencing was used to analyse the bulked RNA samples. A de novo transcriptome reconstruction based on the RNA-Seq data was made, resulting in 45181 contigs, representing 'transcript tags'. These transcript tags were annotated with gene ontology $(\mathrm{GO})$ terms. One of the most striking results from the expression analysis was that the drought sensitive plants were characterised by having approximately twice the number of differentially expressed transcript tags than the tolerant plants after drought. This difference was evident in most of the major GO terms. Before onset of drought the sensitive plants overexpressed a number of genes annotated as senescence-related. Furthermore, the concentration of three metabolites, particularly pinitol, but also proline and malate increased in leaves after drought stress.

Conclusions: This de novo assembly of a red clover transcriptome from leaf material of droughted and non-droughted plants provides a rich source for gene identification, single nucleotide polymorphisms (SNP) and short sequence repeats (SSR). Comparison of gene expression levels between pools and treatments identified candidate genes for further analysis of the genetic basis of drought tolerance in red clover.
\end{abstract}

Keywords: Drought stress, Polymorphism, Red clover, RNA-Seq, Transcriptome assembly, Trifolium pratense

\footnotetext{
* Correspondence: Ifs@aber.ac.uk

${ }^{1}$ Institute of Biological, Environmental and Rural Sciences, Aberystwyth

University, Gogerddan, Aberystwyth, Ceredigion SY23 3 EB, UK

Full list of author information is available at the end of the article
} 


\section{Background}

Red clover (Trifolium pratense L.) is a versatile forage crop legume, which can tolerate a variety of soils and is suitable for silage production for winter feed and for grazing. The benefits of red clover to farming include nitrogen fixation, soil improvement and high nutritive value in terms of protein-rich feed for livestock. Like other legumes, nitrogen fixation is facilitated by nodulation via symbiosis with the soil microbe Rhizobium leguminarosum [1,2]. The nutritional benefits are attributable to easy digestibility, high voluntary intake by livestock and high protein content during ensiling [3]. Red clover can be grown alone or in a sward mixed with grasses and other legumes, where it has been shown to be more productive than monocultures [4]. Red clover is a short lived perennial that usually persists for two to three years, although more persistent varieties are available. Improving its longevity is a major breeding target [2,5]. Persistency is a complex trait, and both biotic and abiotic stresses are known to have a major effect on longevity in the field [2]. Red clover has a tap root system in the first year, but in subsequent years a more fibrous root system develops at the expense of the tap root, which senesce [1]. This is believed to increase susceptibility to diseases of the crown, such as crown rot [1]. Abiotic stresses are other factors considered to be of major importance for persistency $[1,3,5]$. Cold and drought stresses are important components of abiotic stress [6-10]. Even temperate forage crops are exposed to periods of drought that have adverse effects on yield and persistency [11]. However, little is known about its genetic basis in red clover. Two studies have identified quantitative trait loci (QTLs) for traits related to persistence in red clover. Using full sib mapping families [12] found a major QTL for all persistency indices measured on linkage group 3 , with heritabilites varying between 0.28 and 0.66 . Klimenko et al. [13] found QTLs related to disease resistence and winter hardiness particularly on linkage groups 3 and 6 . These studies are useful for future marker assisted selection. RNA-Seq approaches have potential to provide further valuable information about the molecular mechanisms underlying plant responses to abiotic stresses.

Effects of drought on gene expression have been studied using microarrays in rice [14], wheat [15] and Arabidopsis thaliana [16]. These and other studies have provided information about the signalling pathways involved in the response to water stresses [17-19]. A typical response to water stress is to prevent water loss by closing the stomata, and producing abscisic acid (ABA). ABA initiates a signalling cascade which modifies the transcriptome and up-regulates genes encoding a number of proteins and enzymes involved in drought response [20,21]. These can be divided into signalling and response proteins. Signalling proteins include transcription factors, protein kinases and ubiquitin ligases. Drought response proteins include dehydrins, heat shock proteins, aquaporins and scavengers of reactive oxygen species (ROS) [17,22-25]. Additionally, metabolic pathways can be modified to compensate for reduced water and $\mathrm{CO}_{2}$ uptake [26]. Osmolytes such as proline and pinitol are often produced to lower the osmotic potential in order to maintain water uptake and protect against build-up of toxic ion levels [17].

Next generation sequencing (NGS) can provide a depth of sequencing that is sufficient to cover the transcriptome of an organism many fold and allow quantification of the detected transcripts. The Illumina platform has been used for transcriptome analysis in several plant species [27-32]. An Illumina HiSeq2000 instrument can produce hundreds of millions of paired end reads per flow cell [33-35]. Gene expression is quantified by counting the number of reads per kilobase of transcript per million mapped reads (RPKM), enabling quantitative comparisons to be made [36]. A complication arises with short reads if there is no reference sequence to map the reads onto. In the case of model organisms extensive genomic and transcript sequence data are available, but for non-model organisms the amount of expressed sequence tags (ESTs) and other transcript sequence data available to use as a reference can vary dramatically. Paucity of data in the reference transcriptome can potentially undermine the unbiased potential of NGS transcriptome analysis. Fortunately, software specifically designed for de novo reconstruction of the transcriptome from short reads, is available. A variety of methods using short read assemblers have been described in a number of plant species including Eucalyptus [30], Sonneratia alba [37], chickpea [27], sweet potato [38], alfalfa [28] and lupin [39].

The primary aim of this work was to use NGS technology to study changes in transcriptome patterns in pooled samples of red clover genotypes, contrasting in their phenotypic response to drought. Previous examples of transcriptome analysis have often described effects on seedlings $[14,16,40]$ or other shorter term drought treatment. In this work we used mature plants in an experimental set-up designed to mimic field conditions as closely as possible. The plants were F1 progeny of a full sib mapping family. Based on growth rates and relative water content (RWC) we identified two bulks of genotypes contrasting in their response to drought stress. The Illumina platform was used to sequence four pools of RNA samples, two from the drought tolerant bulk before and after drought stress, and two from the sensitive bulk. It enabled us to assemble de novo a transcriptome library of red clover from paired end reads. As this study was made on genotypes from a mapping population, it also provided an opportunity to mine the pooled samples for putative SNP and SSR polymorphisms. Finally, information about differentially expressed genes informs our understanding of the fundamental aspects of drought response and identifies potential targets for improved 
abiotic stress tolerance. As part of this study we have also measured the concentration of a few key metabolites, known from other studies to undergo major changes in concentration in response to water stress.

\section{Results}

The mapping family described in Methods was used to select a subset of genotypes that contrasted phenotypically in their response to drought stress. Leaf material from the two contrasting pools were used as a source for RNA-Seq data to generate a comprehensive library of transcript tags, and to explore how the two pools responded to drought stress in terms of differences in transcript expression patterns.

\section{Selection of drought tolerant and sensitive genotypes}

Classification of drought tolerant and sensitive genotypes was based on growth rate (mg dry weight (DW) day ${ }^{-1}$ ) and RWC at the end of a two month drought treatment (DW2). Drought tolerant genotypes were selected by identifying plants which exhibited the highest RWC and growth rate at DW2. Sensitive genotypes were chosen from plants with the lowest RWC and growth rate. The relationship between the two phenotypic parameters among 64 genotypes from the mapping family is shown in Figure 1, and the ten plants selected from each group are highlighted. Statistical analysis of the phenotypic data from all genotypes measured under control conditions (DW0) revealed no significant differences between the two groups (Table $1 \mathrm{~A}$ and $\mathrm{B}$ ). The growth rate was significantly higher in the tolerant pool at the mid drought point (DW1), and at the end of the drought treatment (DW2). The reason for the increased growth rate at mid drought (DW1) in both pools is partly that the soil water content was still $42 \%$ compared to $52 \%$ at the start of the experiment (Additional file 1), so the plants did not yet suffer appreciably from drought stress. The other reason is the increasing number of daylight hours and increase in average temperature, during the period of the experiment. The continued increase in growth rate of the tolerant plants even at the later stages of the experiment shows their resilience to this stress. This is also illustrated in the difference in RWC and osmotic potential (OP) between the two sets of genotypes at DW2 (Table 1A and C, Additional file 2).

\section{Red clover transcriptome assembly}

The total RNA from both the drought and control treatments for individual plants of the two selected groups was extracted and quality checked. Out of the 40 RNA samples, two failed RNA quality check, one from the sensitive control pool and one from the sensitive drought treatment pool. The RNA samples which passed quality check were then combined in equal amounts in their respective pools

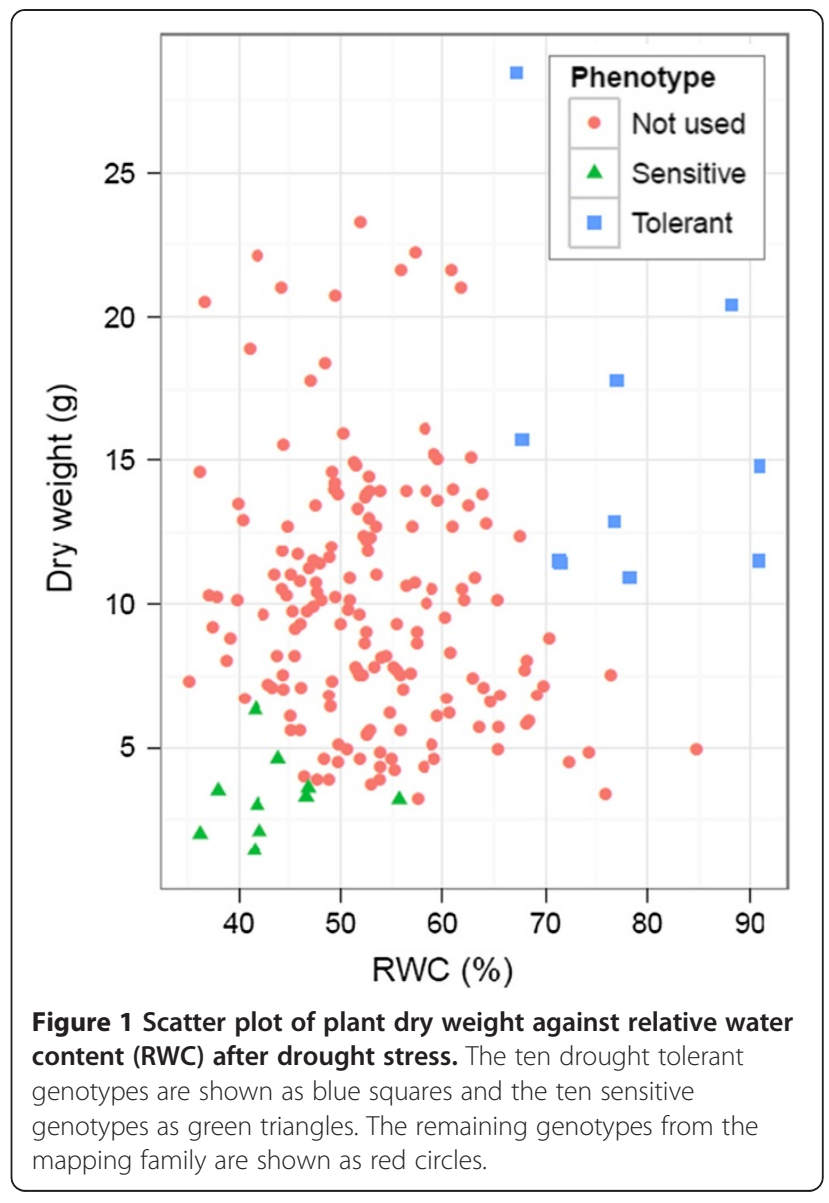

and sent to Eurofins Ltd Genomic Service for sequencing. Over $100 \mathrm{M}$ of $100 \mathrm{bp}$ paired end reads were generated after quality checking by Eurofins. De novo transcriptome reconstruction of the data was made using RNA-Seq reads and publically available red clover EST sequences. Given the mixed sequencing data, i.e. the short reads produced in this work and the publically available red clover EST sequences (mostly Sanger sequences), this constitutes a hybrid assembly. This approach generated 45181 contigs (denoted 'transcript tags' hereafter) constituting $42 \mathrm{Mbp}$. This Transcriptome Shotgun Assembly project has been deposited at DDBJ/EMBL/GenBank under the accession number GAOU00000000. The version described in this paper is the first one, GAOU01000000. The full list of all transcript tags with their annotation and assignment to GO terms is available in Additional file 3. Other relevant statistics include an average transcript tag length of 933 bp, N50 of 622 bp, 196.4× coverage (actual number of reads mapped/transcriptome length) and longest sequence of $13855 \mathrm{bp}$. To further evaluate the quality of the assembly, all of the reads were mapped back to the assembled transcriptome using CLC Genomics Workbench v4.0.0. Using a paired end distance of up to $1000 \mathrm{bp} 69 \%$ of the reads mapped back. A total of 34534 transcript tags (75\%) 
Table 1 Data for plant growth rate, key metabolites, relative water content and osmotic potential

\begin{tabular}{|c|c|c|c|c|}
\hline \multicolumn{5}{|l|}{ A } \\
\hline \multicolumn{2}{|c|}{ Sampling times } & $\begin{array}{l}\text { Sensitive } \\
\left(\mathrm{mg} \mathrm{day}^{-1}\right)\end{array}$ & $\begin{array}{l}\text { Tolerant } \\
\left(\mathrm{mg} \mathrm{day}^{-1}\right)\end{array}$ & $P$ \\
\hline \multicolumn{2}{|l|}{ DWO } & $33(22-47)$ & $45(37-54)$ & $P=0.119$ \\
\hline \multicolumn{2}{|l|}{ DW1 } & $147(107-204)$ & $286(239-342)$ & \\
\hline \multicolumn{2}{|l|}{ DW2 } & $80(58-109)$ & $336(269-421)$ & \\
\hline \multicolumn{2}{|l|}{ DW3 } & $181(134-244)$ & $369(302-450)$ & \\
\hline \multicolumn{5}{|l|}{ B } \\
\hline \multicolumn{2}{|c|}{$\begin{array}{l}\text { Source of } \\
\text { variation }\end{array}$} & df & MS & $P$ \\
\hline \multicolumn{2}{|l|}{ Pool } & 1 & 1.599 & $<0.001$ \\
\hline \multicolumn{2}{|l|}{ Covariate } & 1 & 0.337 & 0.003 \\
\hline \multicolumn{2}{|l|}{ Residual } & 17 & 0.027 & \\
\hline \multicolumn{5}{|c|}{$\begin{array}{l}\text { Subject*Time } \\
\text { stratum }\end{array}$} \\
\hline \multicolumn{2}{|l|}{ Time } & 2 & 0.196 & $<0.001$ \\
\hline \multicolumn{2}{|c|}{ Time*Pool } & 2 & 0.179 & $<0.001$ \\
\hline \multicolumn{2}{|l|}{ Residual } & 36 & 0.0163 & \\
\hline \multicolumn{2}{|l|}{ Total } & 59 & & \\
\hline \multicolumn{5}{|l|}{ C } \\
\hline \multicolumn{2}{|l|}{ Trait } & Sensitive & Tolerant & \\
\hline \multirow[t]{2}{*}{ RWC } & Control & $84.2(81.2-87.2)$ & $85.9(81.9-89.9)$ & \\
\hline & Drought & $42.5(40.0-45.1)$ & $78.0(72.5-84.5)$ & \\
\hline \multirow[t]{2}{*}{ OP } & Control & $-1.09(-1.20-(-0.99)) \mathrm{MPa}$ & $-1.14(-1.20-(-1.09))$ & 9)) $\mathrm{MPa}$ \\
\hline & Drought & $-3.60(-4.14-(-3.06)) \mathrm{MPa}$ & $-2.44(-2.86-(-2.03)$ & 3) $\mathrm{MPa}$ \\
\hline \multirow{3}{*}{ Glucose } & Control & $6.94(5.24-9.19)$ & $6.01(4.52-7.98)$ & \\
\hline & Drought & $3.80(2.60-5.55)$ & $6.74(5.39-8.42)$ & \\
\hline & Control & $7.49(5.72-9.81)$ & $6.01(4.57-7.90)$ & \\
\hline Fructose & Drought & $4.77(3.84-5.94)$ & $9.14(6.64-12.60)$ & \\
\hline \multirow{2}{*}{$\begin{array}{l}\text { myo- } \\
\text { Inositol }\end{array}$} & Control & $3.42(2.76-4.26)$ & $3.29(2.90-3.74)$ & \\
\hline & Drought & $2.46(2.16-2.82)$ & $3.28(2.79-3.86)$ & \\
\hline \multirow{2}{*}{ Malate } & Control & 14.6 (10.9-19.5) & $17.9(12.8-24.9)$ & \\
\hline & Drought & $27.6(20.6-36.9)$ & $22.2(20.1-24.5)$ & \\
\hline \multirow{2}{*}{ Proline } & Control & ND & ND & \\
\hline & Drought & $8.51(6.28-10.74)$ & $5.00(2.52-7.48)$ & \\
\hline \multirow{2}{*}{ Pinitol } & Control & $17.1(14.0-20.8)$ & $17.1(14.3-20.4)$ & \\
\hline & Drought & 120.9 (1 10.4-132.3) & $109.6(99.7-120.5)$ & \\
\hline
\end{tabular}

A: Plant growth rate and $95 \%$ confidence intervals (CI) (in brackets) in the sensitive and tolerant pool. DW0 is growth rate at the onset of the drought stress treatment, DW1 is after 16 days, DW2 is at the end of the drought period ( 40 days), and DW3 is growth rate 29 days after the end of the drought stress treatment (recovery). B: ANOVA table for the growth rate data $\left(\log _{10}\right.$ transformed data). The analysis was performed as a repeated measures design with the DW0 (control) as a co-variate. The $P$ value next to the DWO data indicates the significance value for the co-variate only. C: Mean values and $95 \% \mathrm{Cl}$ for relative water content (RWC) (\%), osmotic potential (OP), and 6 metabolites $\mathrm{mg}(\mathrm{gDW})^{-1}$; ND - below detection limit. were assigned a functional name by BLAST against Medicago, Arabidopsis or UNIPROT, and 29189 transcript tags (63\%) were assigned at least one GO term.

\section{Exploration of gene expression}

In total, 6262 transcript tags were differentially expressed ( $>2$ fold) between treatments and pools. The number of transcript tags with increased expression after drought stress were 3546 and 1903, while the number with decreased expression (>2 fold) were 2255 and 1015, in the sensitive and tolerant pool, respectively (Table 2). The full list of differentially expressed transcript tags can be seen in Additional file 4.

The results are also summarised in Figure 2, which shows a heatmap (using Pearsons correlation co-efficient). The overall variation in levels of expression was estimated by recording the coefficient of variation $(\mathrm{CV})$ of each identical transcript tag from the sensitive and tolerant samples. The average of the $\mathrm{CV}$ for all the pairs of transcript tags was $26.1 \%$ before drought (DW0) and $20.2 \%$ after drought (DW2) after filtering out tags with $<2$ RPKM.

Analysis of enriched gene ontology terms derived from differentially expressed transcript tags after drought stress revealed GO terms that were common between the drought tolerant and sensitive pools, and GO terms that were unique to each pool. Figure 3 illustrates the GO terms of transcript tags with differential expression. The number of enriched GO terms in common between sensitive and tolerant genotypes was 162 , while 38 and 83 unique GO terms were different from the expectation for the tolerant and sensitive pools, respectively. Figure 4 shows the number of transcript tags which were overand under-represented in various GO terms. The sensitive pool has a larger number of differentially expressed transcript tags in almost all GO term compared to the tolerant pool. Cellular homeostasis (GO:0019725) indicates changes in the steady state physiology of the plants. A total of 20 transcript tags were over-expressed in the sensitive pool compared to 8 in the tolerant pool, and 42 and 30 were under-expressed in the sensitive

Table 2 Differentially expressed transcript tags in drought stressed red clover leaves compared with control conditions

\begin{tabular}{lllll}
\hline Change & Fold difference & Sensitive & Tolerant & Common \\
\hline \multirow{2}{*}{ Over-expressed } & 10 & 526 & 320 & \\
& 5 & 979 & 598 & \\
& 10 & 3546 & 1903 & 1592 \\
Under-expressed & 5 & 689 & 137 & \\
& 2 & 1254 & 322 & \\
\hline
\end{tabular}

Results were partitioned between over and under-expressed and the magnitude of difference (fold) in the sensitive and tolerant pools relative to the control. 


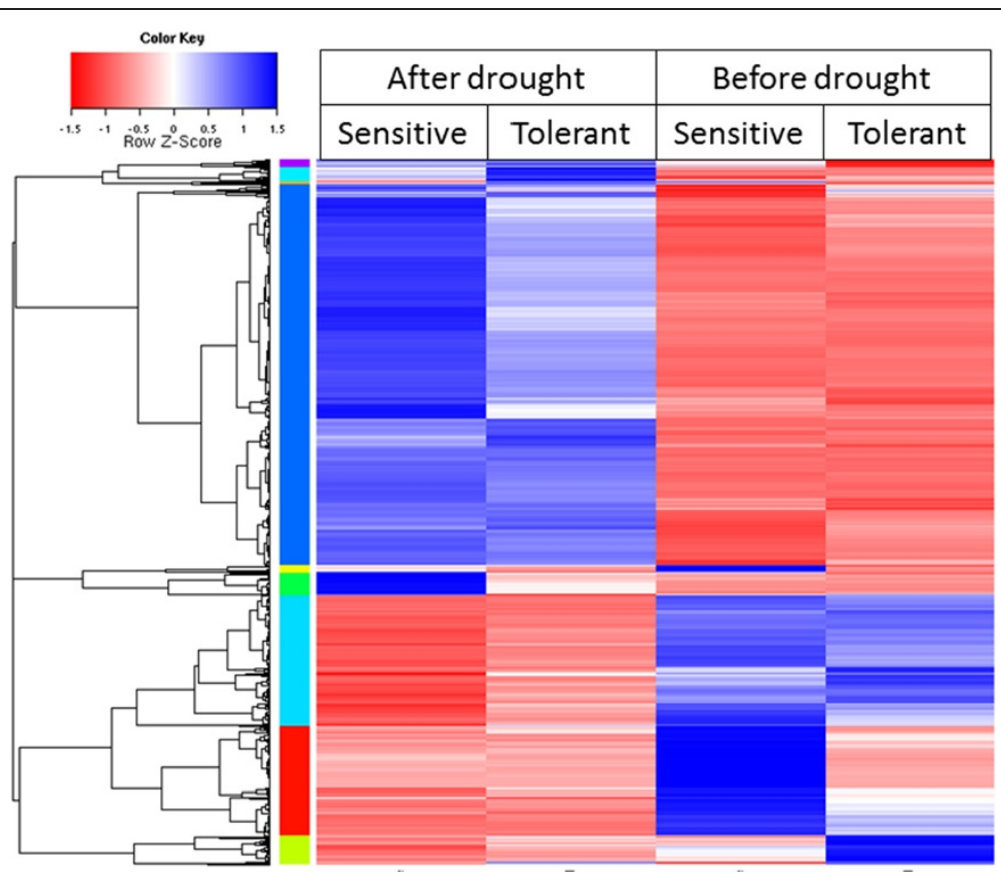

Figure 2 Clustering analysis of differentially expressed transcript tags. Heat map of Pearsons correlation across 6350 differentially expressed transcript tags. A dendrogram of correlation between transcript tags is shown to the left of the heatmap.

and tolerant pools, respectively. In the photosynthesis related categories, the following GO terms are highlighted in Figure 3: photosynthesis (GO:0015979), pigment metabolic process (GO:0042440) and plastid organization (GO:0009657). A significant number of transcript tags was down-regulated in all these GO terms. In the metabolism category the highlighted terms represent regulation of metabolic process (GO:0019222), glucose metabolic process (GO:0006006), carotenoid and terpenoid biosynthetic process (GO:0016177, GO:00016114, respectively) and proline biosynthesis process (GO:0006561). Additionally, the following transporter GO terms were found: Myo-inositol,

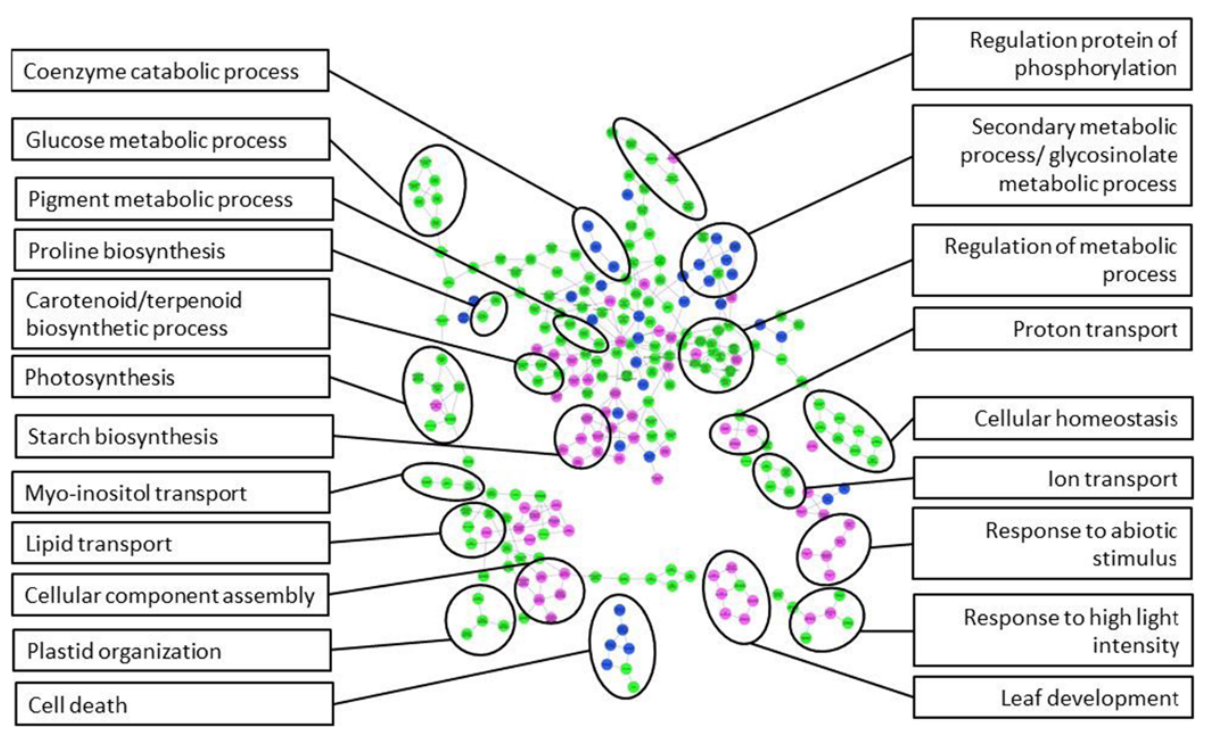

Figure 3 Map of enriched GO after drought treatment in sensitive and tolerant phenotype pools. The map shows parent/child connections between $\mathrm{GO}$ terms. GO terms are coloured based on significance in two enrichment tests for tolerant and sensitive pools. Green: enriched in both pools, pink: enriched only in sensitive pools and blue: enriched only in tolerant pool. The GO map is annotated with black circles which are linked to summary GO terms, see text for discussion and GO terms. 


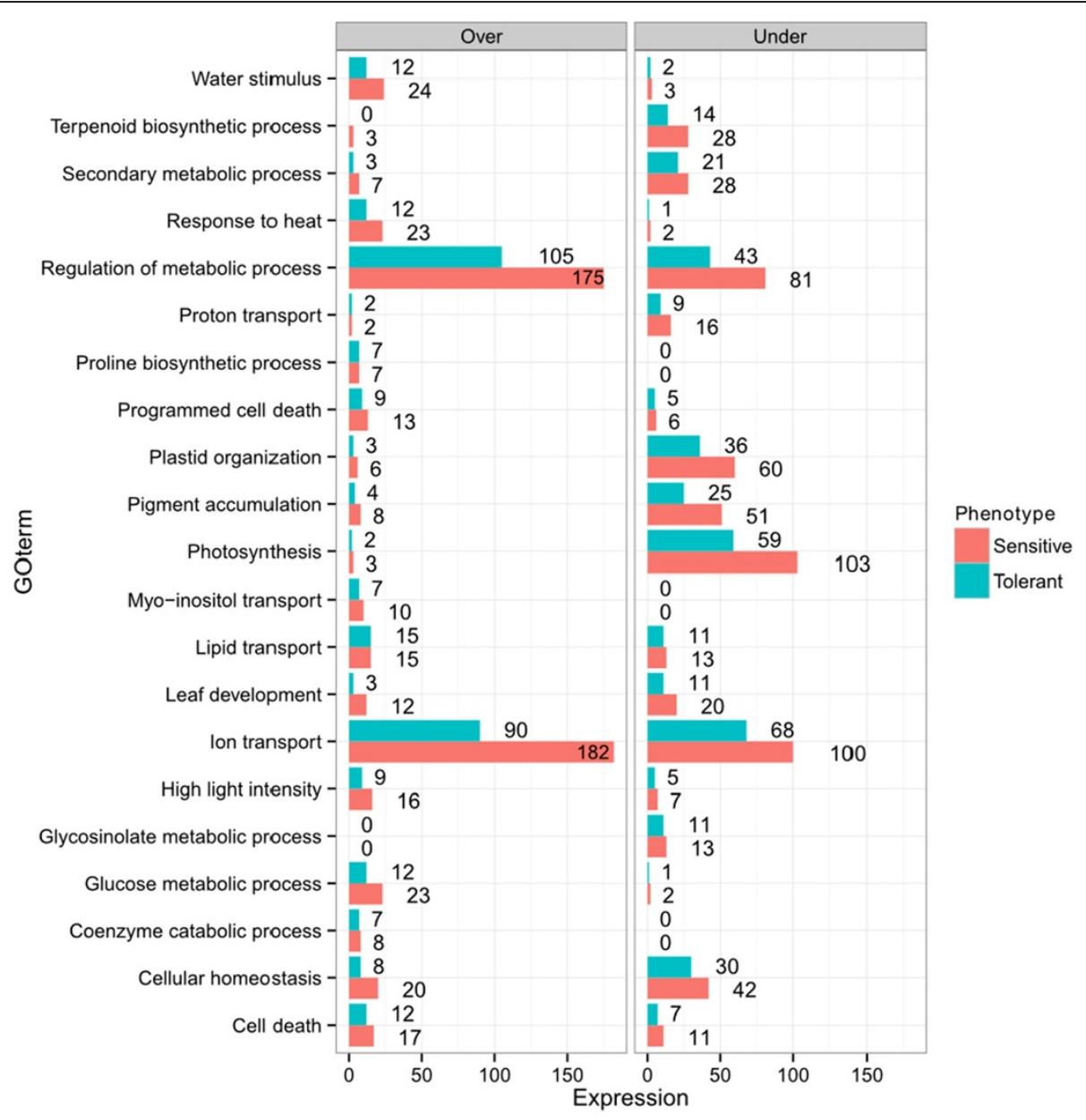

Figure 4 Number of differentially expressed transcript tags after drought stress. The data show the number of transcript tags that are over and under-expressed in the tolerant and sensitive pools. The graph shows the GO term on the $y$-axis and number of differentially expressed transcript tags at the end of each bar, for each GO term.

lipid and ion transport (GO:0015798, GO:0006869 and GO:0006810). A number of stress-related GO terms were found in all pools including response to high light intensity (GO:0009644) and cell death (GO:0008219). However, we found that programmed cell death-related terms were specifically enriched relative to expectation in the tolerant pool after drought stress (GO:0012501). Differential expression in response to drought was identified specifically in the tolerant pool for transcript tags relating to $\mathrm{GO}$ terms for coenzyme catabolic process, secondary metabolic processes, glycosinolate metabolic processes (GO:0009109, GO:0019748 and GO:0019757, respectively). In the sensitive pool differentially expressed transcript tags related to unique GO terms included proton transport (GO:0015992), starch biosynthesis process (GO:0019252) and leaf development (GO:0048366), as well as a number of abiotic stress GO terms including response to water stimulus (GO:0009415) and response to heat (GO:0009408). Specifically, a transcript tag encoding the key ABA biosynthesis enzyme 9-cis-epoxycarotenoid dioxygenase (NCED1) (RC.21240) was over-expressed in response to drought stress in both pools. Another notable result is that most leucine rich repeat receptor kinases were under-expressed in both pools in response to drought (Additional file 4). These proteins are known to be involved in signal transduction pathways for a range of developmental and defence-related processes, including hormone perception and wound response [41].

While the effect of drought on gene expression was the main focus, we also looked at differences in gene expression between tolerant and sensitive pools under control conditions. The results are shown in Additional file 4 in the 'control' tab. The tolerant pool over-expressed 163 ( $>2$ fold) transcript tags compared to the sensitive, which in turn had 436 up-regulated transcript tags. We inspected the data manually for gene functions or pathways and in the tolerant pool we found no consistent patterns in the data and interpret this as natural variation due to transcriptome 
plasticity. In the sensitive pool we identified eight senescence related proteins (RC.3083, 4561, 7070, 7319, 7433, 10857, 19071, 40938), which were up-regulated compared to the tolerant genotypes prior to drought stress.

\section{qRT-PCR}

To confirm a few of the results from the RNA-Seq work four transcript tags were selected for qRT-PCR analysis. These included three transcript tags, which were differentially expressed (RC.5535 (Matrix metalloprotease), RC.44391 (unknown), and RC.21240 (9-cis-epoxycarotenoid dioxygenase)) and one transcript tag which was expressed constitutively (RC.31500, (ATP synthase delta chain)). The results are shown in Figure 5. For two transcript tags (RC.5535 and RC.44391) the results from the qRT-PCR closely matched the results from the RNA-seq. In the case of RC.21240 the results show a similar trend towards up-regulation, but the fold change in expression is a magnitude higher in the qRT-PCR analysis. The expression level of RC.31500 did not change between treatments in the RNA-Seq experiment, while the qRT-PCR showed a down-regulation as a result of the drought treatment.

\section{SNP and SSR mining}

SNP analysis identified 27922 bi-allelic SNP in 7178 transcript tags. This represents on average a SNP per $1.5 \mathrm{~kb}$ of transcriptome. The mean distance between SNPs in the 7178 transcript tags containing SNPs was $240 \mathrm{bp}$. The distribution of SNPs is shown in Figure 6. A total of 462 transcript tags had more than 10 SNPs within them and they accounted for $28 \%$ of the total number of SNPs identified. The 10 SNP-richest transcript tags totalled $17429 \mathrm{bp}$, and contained 519 SNPs, which is about one SNP per $34 \mathrm{bp}$. The high number of SNPs thus is not due to increased length of the transcript tags. We cannot exclude the possibility that some of them represent paralogous genes, which have been erroneously merged in the assembly process. Transcripts containing single, double or triple SNPs amounted to 2377, 1387 and 859 respectively, accounting for $27.7 \%$ of the total number of SNPs. Details of the putative SNPs are shown in Additional file 5. It should be noted that stringent criteria were used to identify these SNPs (see Methods). This means that SNPs were detected in transcript tags with high expression levels. This stringency means that the number of SNPs reported here is likely to be an underestimation of the total number of SNPs in the transcriptome. On the other hand the confidence level in the SNPs listed in Additional file 5 is high. The SNPs will still need to be validated, but their annotation indicate potential polymorphisms in drought and cold regulated transcript tags, as well as ABA responsive elements, and numerous other potential abiotic stress candidate genes (Additional file 5). The fact that the

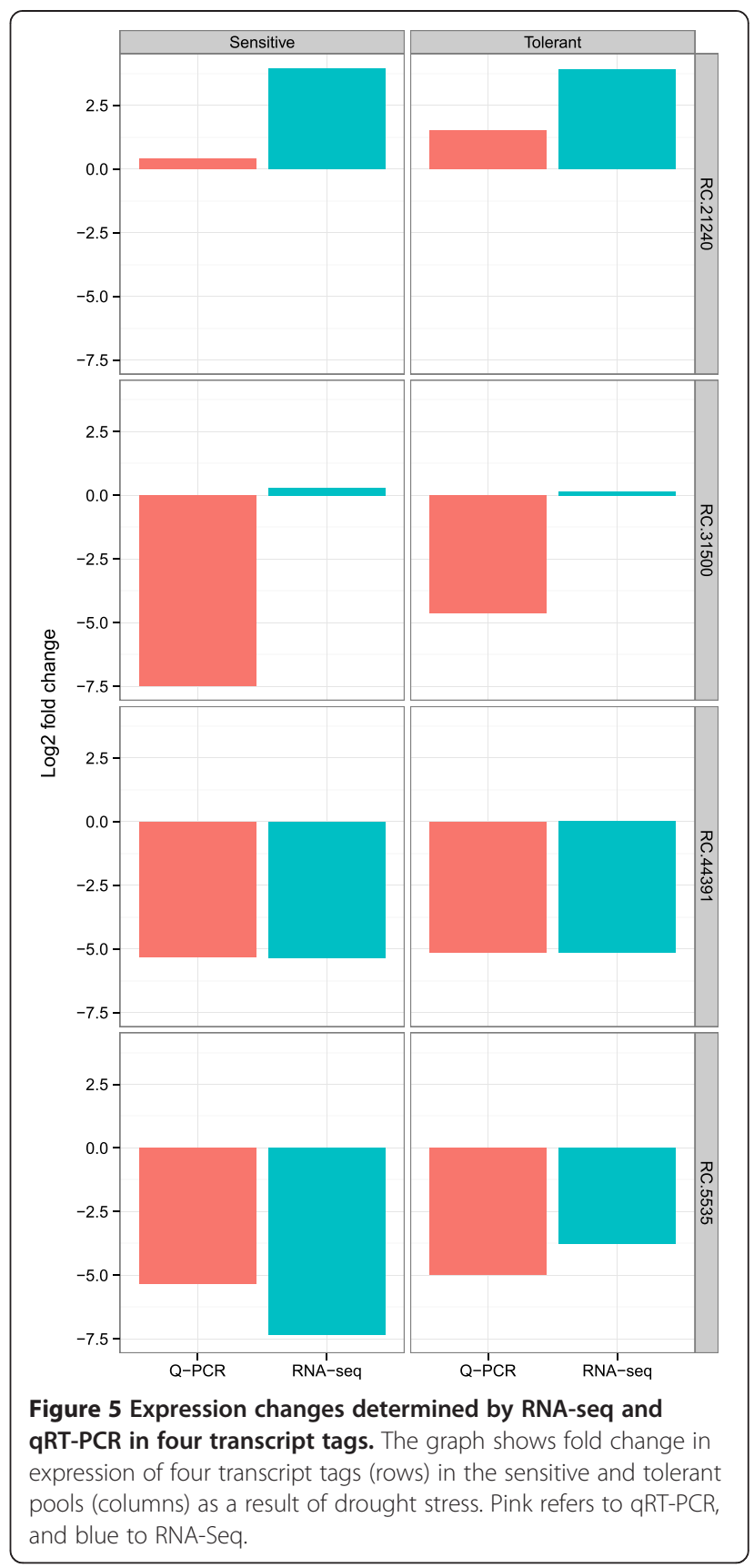

polymorphisms have been identified in genotypes from a full sib family makes genetic mapping of them easier.

The transcript library assembled here also represents a rich source of material for potential transcript-anchored SSR markers. The MISA Perl script (http://pgrc.ipk-gatersleben.de/misa) was used to search for such sequences in the assembly. The results are summarised in Table 2. In total, 3127 SSRs with 2-6 repeat units were identified in $41.9 \mathrm{Mb}$ of transcript sequence data, which amounts to one SSR per $13.42 \mathrm{~kb}$. The number of SSR containing transcripts represented approximately $6 \%$ of the total. The largest proportion of SSRs (60\%) consisted of tri-nucleotide 


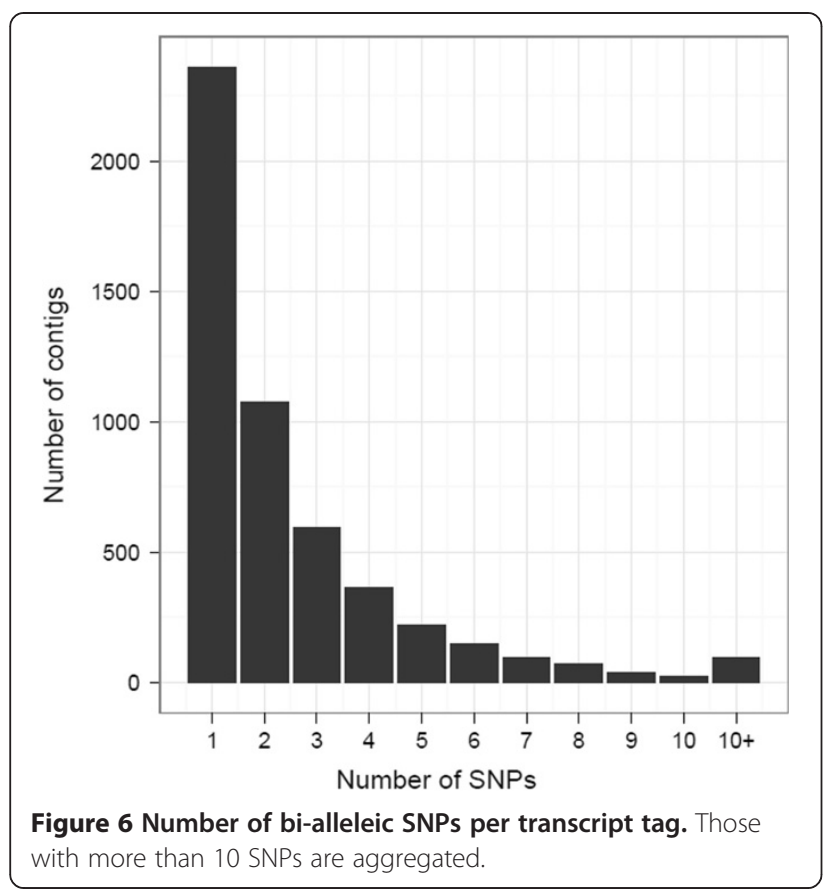

repeats, with about half as many di-nucleotide repeats. The higher complexity nucleotide repeat SSRs were present in progressively smaller, but still significant, numbers (Table 3 ). Additional file 6 provides a list of the transcript tags containing SSR motifs, and Additional file 7 is a list of primer pairs designed for amplification of 2193 of the 2744 transcript tags containing SSRs.

\section{Metabolite analysis}

The metabolite analysis data summarised in Table $1 \mathrm{C}$ show that pinitol, proline and malate all increased in concentration following exposure to drought, while glucose, fructose and myo-inositol remained unchanged. Particularly pinitol concentration rose dramatically from a little over $1.5 \%$ of dry matter to over $10 \%$ during the course of drought exposure. While proline concentration also rose significantly, it was from a very low base (undetectable), and the overall concentration of this metabolite was much lower than pinitol. Malate concentration was also measured. It can be formed by combining $\mathrm{CO}_{2}$ with phosphoenol pyruvate under conditions of limiting $\mathrm{CO}_{2}$ availability, such as stomatal closure $[42,43]$. In $C_{4}$ plants malate is shuttled between mesophyll and bundle sheath cells, where it is decarboxylated, and recycled. Given that water stress leads to stomatal closure and decreased $\mathrm{CO}_{2}$ availability, it seemed reasonable to look for changes in malate concentration in response to drought stress. While the concentration of malate increased (Table 1C), we did not observe convincing evidence for significant changes in expression of transcript tags encoding any of the key enzymes in $\mathrm{CO}_{2}$ metabolism which would be necessary for a malate shuttle.
Table 3 Breakdown of SSR repeats present in the red clover transcriptome assembly

\begin{tabular}{ll}
\hline SSR data & \\
\hline Number of seqs searched & 45181 \\
Total size of sequences (bp) & 41943532 \\
Number of SSRs & 3127 \\
Number of SSR containing seqs & 2744 \\
Number of seqs containing more than one SSR & 322 \\
Number of compound SSRs & 192 \\
\hline Distribution of SSR repeat types & \\
Di-nucleotides ( $\geq 8$ repeats) & $907(29 \%)$ \\
Tri-nucleotides ( $\geq 6$ repeats) & $1879(60 \%)$ \\
Tetra-nucleotides ( $\geq 5$ repeats) & $235(7 \%)$ \\
Penta-nucleotides ( $\geq 5$ repeats) & $53(2 \%)$ \\
Hexa-nucleotides ( $\geq 5$ repeats) & $51(2 \%)$ \\
\hline
\end{tabular}

This includes phosphoenolpyruvate carboxylase, NADPdependent malic enzyme, malate dehydrogenase and pyruvate-orthophosphate dikinase.

\section{Discussion}

This work has generated a large amount of sequence data with NGS technology in a non-model crop species. Although red clover previously had a number of resources available, such as an EST database [44] the work described here, has greatly increased the number of transcript sequences available. The high number of sequenced reads resulted in significant coverage of the transcriptome in leaves, allowing gene discovery, quantification of transcripts in four pools and the identification of putative SNPs and SSRs.

In this experiment we used mature plants in a long term (60 days) experiment to simulate the effects of drought as realistically as possible in a greenhouse environment. Many drought experiments described in the literature involving transcriptomics have used seedlings and/or short term drought treatment which minimises variation due to environmental factors (e.g. [14,16]). While long term experiments are likely to introduce more variation between genotypes and replicate plants, it may also provide potentially novel information on how the plant responds to prolonged periods of water deficiency. A large number of transcript tags were differentially expressed in response to the drought stress in both the sensitive and tolerant plants (Table 2), but variation in expression levels (the average $\mathrm{CV}$ of RPKM values of pairs of tags from the sensitive and tolerant pools) was slightly larger before than after drought. We used a pooling strategy to reduce within and between pool differences. This approach has been widely used in RNA-Seq experiments to study for example cell wall composition in Alfalfa [28], berry development in Vitis viniferia [29], tissue specific expression in Eucalyptus 
[30] and floral sex determination in cucumber [31]. Barcoding of the four pools enabled multiplexing libraries on a single lane of the flow-cell. This reduced possible confounding effects arising from between-flow-cell differences [45]. It is also interesting to note that expression levels before drought were similar in both pools for $99 \%$ of the transcript tags. This suggests that the differences in gene expression which we observed in the two sets of genotypes at the end of the drought stress period are likely to represent a response to the drought stress rather than a difference between the two pools per se.

In the qRT-PCR experiment three out of four of the transcript tags tested showed similar changes in expression as was observed in the RNA-Seq experiment. The reasons for the discrepancy between the two methods for RC.31500 are not clear to us. While our data represent a small sample, the results are however of a similar nature to those reported in [29]. They found that 12 out of 15 genes matched the expected RPKM values when quantified using qRT-PCR.

The results reported here represent a platform for further examination of candidate genes with a potential role in plant response to drought stress. The total size of the transcriptome assembled was $42 \mathrm{Mb}$. This constitutes around $10 \%$ of the predicted genome size $(440 \mathrm{Mb})$ [44]. Approximately $46 \mathrm{k}$ transcript tags were generated in the transcriptome reconstruction. This is similar to those found in Medicago truncatula (44124 gene loci) [46], Soybean (46430 protein coding genes) [47] and Arabidopsis (37019 gene models) [48]. The number and total size of transcripts naturally vary for de novo assemblies of other species, such as in chickpea (55 k) transcripts (28 Mb) [27], Sonneratia alba, $30 \mathrm{k}$ transcripts (18 Mb) [37] and Eucalyptus, $18 \mathrm{k}$ transcripts (22 Mb) [30]. An 8 fold coverage filter on contigs was used in Eucalyptus, and a $2 \times$ minimum coverage in $S$. alba. This would explain the smaller numbers found in those transcriptomes. Using the same filters for RPKM a similar number of transcript tags would be realised in the present experiment. Due to the heterozygous and allogamous nature of red clover it is likely, that there is some redundancy in our transcriptome assembly. The transcriptome size may thus be overestimated. On the other hand, erroneously merged assemblies would lead to underestimation of the transcript numbers. The SNP detection process showed that 462 transcript tags had greater than 10 SNPs (Additional file 5), which may suggest that the assembly process in those cases merged paralogues or that the reads could be miss-aligned. The allogamous nature of red clover and the pooling strategy used in the experiment makes it challenging to distinguish with certainty between allelic variants and paralogous genes. Therefore it is reasonable to assume there are a few inconsistencies in the assembled transcriptome. Nevertheless, the majority of the transcript tags do have high coverage and have high similarity to known transcripts.

In this experiment the level of water stress as measured by soil water content was identical across bins at the time of sampling during the drought treatment (Additional file 1). Nevertheless, the sensitive and tolerant plants showed contrasting responses to the same level of soil moisture. The sensitive genotypes had a RWC of approximately $43 \%$ (Figure 1). In contrast, the tolerant genotypes had a RWC of $78 \%$, which is only slightly below what is found in nondroughted plants ( 85\%) (Table 1C). This difference manifested itself by the observation that more than twice the number of transcript tags was differentially expressed in the sensitive pool compared to its control, than was the case in the tolerant pool compared to its control. It would be difficult to infer which differentially expressed transcript tags qualify as genes directly involved in response to the drought stress, and as candidates for targeting in genetic improvement programmes. Nevertheless, the results do provide a comprehensive overview of gene expression changes after drought stress. The number of differentially expressed transcript tags which were detected as a result of the drought treatment (Additional file 4) are similar to those reported in other species such as rice (3097 up, 2391 down) [14], wheat (3056 differential) [15] and Arabidopsis (2059 up and 2075 down) [16], albeit for shorter term drought stress.

There was a large degree of overlap between GO terms of differentially expressed transcript tags between the sensitive and tolerant pools in their response to drought. The main difference is that a larger number of transcript tags from the sensitive pool with the same GO terms were either up-regulated or down-regulated in response to the drought, compared to the tolerant pool (Figure 4). The reason for this is not clear, but could simply be a consequence of the degree of severity of the stress experienced by the plants in the two pools. Down-regulation of the photosynthetic apparatus also involves more genes in the sensitive pool than the tolerant, possibly also caused by the difference in sensitivity to the stress (Figure 4). The results contrast with those of [49], who found that more genes were up-regulated in tolerant barley genotypes than in sensitive. Comparisons with short term drought experiments are however, difficult to make. The gradual onset of drought conditions in the present experiment may elicit the differential expression of more genes to counteract the severity of the stress. Nevertheless, even the relatively modest reduction of $\sim 10 \%$ in RWC observed in the tolerant pool, elicited a significant transcriptome response albeit after prolonged water limitation.

Another finding is the high number of senescencerelated transcript tags that were up-regulated in the sensitive pool in non-droughted plants. Perhaps the sensitive plants have a predisposition for reduced growth and less 
stress tolerance [50]. Chaves et al. [19] suggested that plants not predisposed to early senescence may be of value for breeding purposes. Identification of molecular markers or other biomarkers associated with these differences could potentially assist in the removal of such sensitive plants from the gene-pool in a population-based breeding programme. In two of those transcripts (RC.7319 and RC.19071) SNPs were identified (Additional file 5).

The transcript tags which were differentially expressed are similar to those from other drought studies where large transcriptome profiling was used [14-16]. They can be divided into three main groups: functional, regulatory and photosynthesis related genes. Functional drought response genes include protection enzymes (LEA, heat shock proteins, ROS scavenging), osmolyte biosynthesis (proline, trehalose, pinitol/ononitol), transporters (aquaporins, sugar transporters). Regulatory proteins include transcription factors (MYB, NAC, DREB and zinc finger), and those involved in post-transcriptional modification (splice factors, DEAD-box) and post-translational modification, (ubiquitin ligases, protein kinases) and epigenetic factors (histones) [15-17]. When plants are unable to use or dissipate absorbed light energy, the excess energy leads to production of ROS which can cause oxidative damage to the photosynthetic machinery [19]. Under prolonged drought stress, the photosynthetic machinery is down-regulated [51]. This is also the case in this study, where particularly transcript tags encoding Rubisco and polypeptides involved in PSII and PSI were down-regulated (Additional file 4). The rate of recovery of the plant after drought is tightly linked to photosynthetic recovery [18]. Therefore plants which maintain larger portions of their photosynthesising apparatus would have an advantage over those with a lower portion once the stress is alleviated.

Three metabolites known to accumulate in plants in response to drought were measured in this work. Pinitol accumulation was most dramatic and statistically significant (Table $1 \mathrm{C}$ ). We therefore tried to identify a candidate gene likely to represent the O-methyl transferase activity required for the key step in the biosynthesis of pinitol from myo-inositol [52]. The greatest homology with the orthologue in the ice-plant (Mesembryanthemum crystallinum) was RC.4122, but when we did a BLAST search with that as the query, most of the best hits were to genes annotated as caffeic acid-O-methyl transferase. Furthermore, expression of RC.4122 did not increase in response to drought. One explanation could be that the accumulation of pinitol took place early in the drought stress period, and expression of the gene had declined by the end of the drought period. That seems unlikely, since transcript tags annotated as two of the key enzymes in proline biosynthesis were over-expressed in both the sensitive and the tolerant pool in response to drought (e.g. RC.34920: pyrroline-5carboxylate reductase $\left(\mathrm{P} \leq 7.99 \times 10^{-5}\right)$, and $\mathrm{RC} .35692$ :
$\Delta^{1}$-pyrroline-5-carboxylate synthetase $\left(\mathrm{P}<10^{-200}\right)$ (Additional file 4). However, the similarity between most O-methyl transferases makes accurate annotation more challenging. It is surprising to us though, that this gene does not appear to have been identified in any legume despite the high concentration of pinitol and other polyols in this family [53-55].

\section{Conclusions}

This work makes available the first transcriptome library of red clover using next generation sequencing technology. The library was constructed using two pairs of pools of ten genotypes from an $F_{1}$ mapping family. RNA from the two pairs of pools (drought sensitive and drought tolerant, as determined by phenotypic analysis) was extracted before and at the end of a 60 day period of drought. The RNASeq analysis provided a total of 45181 transcripts longer than $200 \mathrm{bp}$. A large number of transcript tags involved in the photosynthetic apparatus were down-regulated in both the sensitive and tolerant pools, but particularly in the former. A great many transcription factors, genes involved in protein modification and degradation were up-regulated in both pools after drought, but again, particularly in the sensitive pool. As expected, a number of genes involved in ABA biosynthesis and abiotic stress signal transduction were also up-regulated. The general trend was that a larger number of genes were up-regulated in the sensitive pool than in the tolerant. Despite the highly significant increase in the concentration of the compatible solute pinitol, we were unable to definitively identify the gene encoding the O-methyl transferase responsible for the key step in pinitol biosynthesis from myo-inositol. We recognise the limitations of the quantitative aspects of this work, and that further validation of the assembly is needed, but the results presented here provide a valuable resource for future work in terms of SNP identification, and annotation of genome sequence assembly currently in progress.

\section{Methods}

\section{Plant material and experimental setup}

The mapping family used throughout consisted of progeny from a $F_{1}$ pseudo-testcross derived from a single genotype from each of two varieties, Milvus and Britta. The plant material was generated initially using a clonal cutting method from the original plant material involving excision of stem regions with nodes followed by auxin treatment and rooting in soil. Subsequent clones were generated by clonal splitting [56]. We made use of 64 genotypes from the mapping family. Three blocks were used in the experimental design, where each block constituted one clone of each of the 64 genotypes. Each block consisted of two drought bins in a randomised block design, i.e. 32 plants per bin and 64 plants per block. The 'drought bins' measured $80 \mathrm{~cm}$ by $110 \mathrm{~cm}$, with a depth of $80 \mathrm{~cm}$. The bins 
were filled with gravel up to $30 \mathrm{~cm}$ : the remaining $50 \mathrm{~cm}$ was filled with John Innes Number 3 compost. Prior to the start of the experiment the bins were watered to field capacity.

Plant material was grown to mature size in $15 \mathrm{~cm}$ pots before transfer to drought bins on 06/03/2010. Plants were then allowed to adjust 2 days to the new environment before cutting back to approximately $6 \mathrm{~cm}$ height above soil level. Then the bins were watered daily to maintain field capacity ( $55 \%$ soil moisture content) until the plants reached a mature size on 15/04/2010, at which time they were sampled for multiple phenotypic traits as described below. This was designated as DW0. From then onwards all watering ceased. Plants were cut again on $05 / 05 / 2010$, and dry weight was recorded. This was designated as DW1. The subsequent sampling time for individual bins (designated DW2) was done when soil moisture content was down to $14 \%$ (see next section for details). This happened between 13-18/06/2010. All phenotypic traits were sampled at this point. Subsequently, the bins were fully hydrated and continually watered until the last cutting on 16/07/2010. This was designated DW3. Growth rate was quantified as dry weight divided by the number of days of growth since the previous cut.

\section{Soil moisture, relative water content and osmotic potential}

Two access tubes for Delta-T PR1 Profile probes were inserted into each drought bin. They were placed equidistant from the edge and $30 \mathrm{~cm}$ apart. The soil moisture content was measured using Delta-T PR1 Profile probe and Delta-T HH2 moisture meter at soil depths of $10,20,30$ and $40 \mathrm{~cm}$. The mean of the 4 measurements was used to indicate the water content of the soil in the bin. In addition, five plants per bin were sampled randomly at 8:30 am for measurement of relative water content (RWC). A single leaf sample was excised from each plant and placed in a sealable zip-lock bag on ice before quantifying RWC using the method described by Smart and Bingham [57]. The soil moisture content and RWC were used as indicators of the drought status of the bins and plants, respectively. The final sampling was done when the soil moisture average fell below $14 \%$ and/or the RWC was below $60 \%$.

Samples for measurement of osmotic potential (OP) were collected between $15: 00$ and 16:00, by excising mature leaf material and storing at $-20^{\circ} \mathrm{C}$. OP was then quantified using a Wescor vapour pressure osmometer 5520 (Wescor Inc., USA) as described by the manufacturer.

\section{RNA sampling}

Samples for RNA extraction were collected between 13:00 and 15:00. The youngest fully open trifoliate leaf was used for this. The excised material was stored in $2 \mathrm{ml}$ safe-lock
Eppendorf tubes and then flash frozen in liquid N, before storing at $-80^{\circ} \mathrm{C}$. The leaf sample was ground to a fine powder using a Retsch MM300 mixer mill. RNA was then extracted using the Trizol (Invitrogen, USA) method as described by the manufacturer, with an additional chloroform extraction step added. Total RNA was solubilised in $50 \mu \mathrm{l}$ DEPC-treated $\mathrm{H}_{2} \mathrm{O}$. A $2 \mu \mathrm{l}$ aliquot was taken and diluted 1:5 in DEPC treated water and used for RNA quantification. Quantification was done using BioRad Experion Automated Electrophoresis System with RNA StdSens chips (Bio-RAD Laboratories Inc., USA), as described by the manufacturer using $3 \mu \mathrm{l}$ of the diluted RNA extract. The data were analysed using Experion ${ }^{\text {tx }}$ Software System operation and data analysis tools, version 3.2.243.0 copyright (c) 2010 Bio-Rad laboratories. Four pooled samples were generated (see Results section), two consisting of 910 drought sensitive genotypes sampled before and at the end of the drought treatment, and two consisting of 9-10 drought tolerant genotypes exposed to the same treatments. For each pool, $2 \mu \mathrm{g}$ of total RNA from each sample was included. Then $500 \mu \mathrm{l}$ of $100 \%$ ethanol was added to each pool, and kept at $-20^{\circ} \mathrm{C}$ during transport.

\section{Sequencing and transcriptome construction}

The four RNA pools were sent to Eurofins Genetic Services (Eurofins, Germany), for sequencing. This included preparation of 4 barcoded libraries, which were multiplexed on a single flow-cell of an Illumina HiSeq2000 (Illumina, USA). The sequencing was done as paired-end reads, $2 \times 100 \mathrm{bp}$ in length. The data was quality checked at Eurofins and provided as four libraries in FASTq format. Sequence quality controls were applied by Eurofins and the read libraries were checked using fastqc (http://www. bioinformatics.babraham.ac.uk/projects/fastqc/). After assembly the contigs were checked for adaptor sequences and none were found.

For the initial construction of the reference transcriptome Velvet [58] was used. Assemblies were created using k-mer sizes of 31, 41, 51 and 61. The 61-k-mer length assembly was chosen for further use because it gave the largest N50, the largest average scaffold size, the largest size of any single scaffold, and the smallest number of scaffolds. This generated $93.4 \mathrm{k}$ contigs. To increase the length of contigs and reduce the number of redundant contigs the Velvet assemblies were combined with existing sequences from the databases from the publically available Trifolium pratense EST library, downloaded from http://www.plantgdb.org/ download/download.php?dir=/Sequence/ESTcontig. The red clover ESTs were combined with the Velvet assemblies by using a second de novo assembly on CLCbio Genomics Workbench version 4.0.0 (31 k-mer). This created 47229 contigs of at least 200 bases in length. In order to retain polymorphism data, conflicting bases found during the assembly process were called 'ambiguously', rather than using 
the 'vote' option. Next, bacterial contigs were removed, by compiling over 4000 bacterial genomes from the NCBI RefSeq database. Then the transcriptome contigs were mapped against the bacterial genomes and un-mapped (non-bacterial) contigs were retained. This led to the removal of 634 contigs. However, to remove the ambiguity for submission to NCBI the reads were mapped back to the contigs to give a 'vote' scoring.

Transcript tag expression was determined using the method described by [36] and executed in CLC. For identification of differentially expressed transcript tags statistical analysis described by [59] was used. A false discovery rate (FDR) of 0.05 was used as the threshold for significance.

\section{Annotation and gene ontology analysis}

BLASTX was used with minimum E-value 1e-15 for annotation of transcript tags. Sequentially, contigs were searched using BLASTX against the following protein databases Medicago truncatula (v3.5, [46]), Arabidopsis thaliana (TAIR10, [48]) and the Universal Protein Resource (UniProt, [60,61]). From each BLAST output the best match was used to annotate the transcript tags. After each BLAST search annotation tags with no matches and ones with 'hypothetical', 'predicted' or 'unknown' annotations were extracted for next sequential BLAST search (order: Medicago - Arabidopsis - UniProt). For GO assignment corresponding GO terms were downloaded from relevant databases. A small number of tags annotated as fungal were removed by manual curation.

TopGO from Bioconductor in R (http://www.r-project. org/) was used to identify enriched GO terms. This was done for all differentially expressed genes, split between over- and under-expressed transcript tags identified by CLC, for each pairwise comparison. The Fishers test implemented in TopGO was used to identify enriched GO terms relative to its expectation. GO terms with a $P$-value $<0.01$ were selected. Both common and unique GO terms were identified by intersection of the data, including those unique to individual pools. Cytoscape [62] was used to visualise the selected GO terms. The GO map for A. thaliana was downloaded and installed in Cytoscape, the enriched GO terms were selected and a sub-network was created for visualisation of the GO network.

\section{qRT-PCR}

Aliquots of the RNA extracts were DNAse treated with the Ambion DNA-Free ${ }^{\text {tm }}$ kit (Ambion, USA), according to the manufacturer instructions. The cDNA synthesis was done using Invitrogen ${ }^{\text {Tw }}$ Superscript ${ }^{\text {Tw }}$ II reverse transcriptase (RT) (Invitrogen, USA) as described by the manufacturer using an Oligo $(\mathrm{dT})^{25}$ Primer with $50 \mathrm{ng}$ total RNA. Samples were then treated with RNaseH (Promega, USA) and stored at $-20^{\circ} \mathrm{C}$. All qRT-PCR work was done using an Applied Biosystems (USA) 7500 Real time PCR system. The 7500 system sequence detection software version 1.2.3 was used for analysis including auto $\mathrm{Ct} / \mathrm{CP}$ (cross threshold/crossing point), mean $\mathrm{CP}$ and outlier removal at $95 \%$ confidence). All samples were run in triplicate using the following PCR concentrations in a volume of $10 \mu \mathrm{l}$ : $5 \mu \mathrm{l}$ SYBR Green master mix (Applied Biosystems, USA), 900nM forward and reverse primers (Biolegio, Netherlands), and $1 \mu \mathrm{l} 10 \times$ diluted cDNA. All primers were designed using the Roche Universal ProbeLibrary Assay Design Center at https://www.roche-applied-science.com/ sis/rtpcr/upl/index.jsp?id=UP030000. The following amplification program was used: $95^{\circ} \mathrm{C}$ for $10 \mathrm{~min}, 40$ cycles at $92^{\circ} \mathrm{C}$ for $15 \mathrm{~s}$, annealing temperature for $30 \mathrm{~s}, 72^{\circ} \mathrm{C}$ for $45 \mathrm{~s}$ followed by a final elongation at $72^{\circ} \mathrm{C}$ for $10 \mathrm{~min}$. The specific annealing temperatures and nucleotide sequence of the primers are shown in Additional file 8. The relative expression software tool (REST-384) was used to calculate the relative fold change in gene expression (http://www.genequantification.info/) [63] using the mathematical model described by Pfaffl [64]. Primer efficiencies were measured using a serial dilution of stock cDNA at 1:1, 1:10 and 1:100. Every plate included three negative controls for detection of contamination. RC.44146 was used as the reference gene. This was the Actin gene, which was found not to be differentially expressed in the RNA-seq data analysis. For comparison between RNA-seq and qRT-PCR data, the fold change in expression of drought stressed samples was calculated relative to control samples for both RNA-seq and qRT-PCR data.

\section{SNP and SSR mining}

The SNP detection tool in CLC was used to identify SNPs. All reads were included in this process. The minimum count for the variant allele was 200 and window length was $17 \mathrm{bp}$. For identification of SNPs inherited from one heterozygous parent and one homozygous parent, the minimum variant frequency was set to $20 \%$ to allow variation from the expected haplotype frequency of $25 / 75 \%$.

The MISA (Microsatellite) Perl script (http://pgrc.ipkgatersleben.de/misa) was used for identification of SSRs. The settings for minimum number of repeats were as follows: Di-nucleotide 8; Tri-nucleotide 6; and Tetra, Penta and Hexa-nucleotide repeats 5. For compound SSRs the maximum distance between two SSR runs was $50 \mathrm{bp}$. The BatchPrimer3 programme [65] was used to design primers pairs for amplification of the SSR motifs. The default settings were used except for the annealing temperature, which was set for an optimum of $60^{\circ} \mathrm{C}$.

\section{Metabolite sampling and extraction}

Whole young trifoliate leaf samples were collected for metabolite quantification between 11:00 and 13:30. They were stored on ice in re-sealable plastic bags, until an amount 
of 20-60 mg was weighed. This was stored in $2 \mathrm{ml} \mathrm{safe-}$ lock microfuge tubes (Eppendorf, Germany) before they were flash frozen in liquid $\mathrm{N}_{2}$ and then stored at $-20^{\circ} \mathrm{C}$. Before extraction a metal ball bearing was added to each tube. During this process the samples were kept frozen by brief exposures to liquid $\mathrm{N}_{2}$. This was also the case when the samples were homogenized to a fine powder in a Retsch-mill MM300, mixer mill (Retch, Germany) for 2 min (20 impacts/s). Afterwards $300 \mu \mathrm{l}$ of $100 \%$ ethanol was added and mixed for a further 15 minutes (20 impacts/s). Next, $200 \mu \mathrm{l}$ of chloroform $\left(\mathrm{CHCl}_{3}\right)$ was added and mixing continued for 5 minute (20 impacts/s). Then, $400 \mu \mathrm{H}_{2} \mathrm{O}$ was added and the samples were mixed by vortexing, before centrifugation for $5 \mathrm{~min}$ at $14 \mathrm{k} \mathrm{rpm}$ to separate the aqueous ethanol phase from the chloroform phase. The total volume of the aquous ethanol phase was approximately $525 \mu \mathrm{l}$. Two $75 \mu \mathrm{l}$-aliquots were transferred to new microfuge tubes $(1.5 \mathrm{ml})$. The aliquots were dried using a speed vac concentrator for four hours (without heating), with the lids open under vacuum. All samples were then stored at $4^{\circ} \mathrm{C}$.

\section{Determination of metabolite concentration using gas chromatography mass spectroscopy}

Prior to derivatization of the samples two internal standards were added: castanospermine (Enzo life sciences, USA) (20 mg) and cyclo-leucine (Sigma-Aldrich, UK) (20 mg). The samples were dried down completely before derivatizing. Derivatization of the samples was achieved using a 2-step process. First, $30 \mu \mathrm{l}$ of freshly prepared MOX solution (O-methylhydroxylamine hydrochloride in pyridine, Sigma-Aldrich, UK) was added to the dried samples, and kept at room temperature for 2 hours to allow solubilisation. The samples were then transferred to crimp sealed $0.3 \mathrm{ml} \mathrm{GC}$ vials (Chromacol/Fisher, UK), and the vials were heated for 15 minutes at $90^{\circ} \mathrm{C}$ to convert ketone groups to the oxime derivative. The vials were then decapped and $20 \mu \mathrm{l}$ BSTFA (N,O-Bis(trimethylsilyl) trifluoroacetamide) (Sigma-Aldrich, UK) was added. The vials were recapped and heated for a further 15 minutes at $90^{\circ} \mathrm{C}$ to convert remaining polar groups to their trimethylsilyl derivatives. This method is similar to those described by Parveen et al. [66].

Analysis was carried out using an Agilent GC-MS system (Agilent Technologies UK Ltd.) comprising a 5973 network Mass Selective detector, an 6890 Series GC and a 7683 series autosampler. The GC was fitted with a Varian FactorFour $^{\mathrm{Tm}}$ VF-5 ms capillary column $(30 \mathrm{~m} \times 0.25 \mathrm{~mm}$ ID $\times 0.25 \mu \mathrm{m}$ film thickness). The injection volume was set to $1 \mu \mathrm{l}$ with a 1:50 split ratio. The oven was set at an initial temperature of $80^{\circ} \mathrm{C}$ and increased to $280^{\circ} \mathrm{C}$ at a rate of $10^{\circ} \mathrm{C}$ per minute. The inlet temperature was set to $280^{\circ} \mathrm{C}$ and the transfer line to $320^{\circ} \mathrm{C}$. The mass spectrometer was set to scan between 50 and $600 \mathrm{~m} / \mathrm{z}$. For quantification of metabolites standard curves were prepared using standards (Sigma-Aldrich, UK with the exception of pinitol which was purchased from ACROS Organics, Belgium). Quantification was achieved using Enhanced Data Analysis software (ChemStation 1701 CA version 00.00, Agilent Technologies UK Ltd.). Additional file 9 shows the metabolites that were quantified and relevant information for quantification. The quantification of glucose, fructose, myo-inositol and pinitol in non-droughted samples required standard curves ranging from 1-50 $\mu$ g. In droughted samples the higher concentrations of pinitol required the range to be increased to $500 \mu \mathrm{g}$. An additional standard curve was set up for pinitol concentrations above $200 \mu \mathrm{g}$ since the curve was non-linear in the high range.

\section{Statistical analysis of plant growth and metabolites}

The plant growth data were analysed using a repeated measures ANOVA approach with the control data (DW0) as a co-variate. The data were $\log _{10}$ transformed. Because there were only two timepoints for the RWC, OP and metabolite data, we used a split-plot in time ANOVA design for the analysis of those data. The data for glucose, fructose, myo-inositol, malate and pinitol were $\log _{10}$ transformed. The analysis was performed using Genstat, $15^{\text {th }}$ edition (VSN International Ltd (http://www.vsni.co.uk)).

\section{Availability of supporting data}

All the sequencing data have been deposited in the NCBI short read archive under the Bioproject PRJNA219226 (http://www.ncbi.nlm.nih.gov/bioproject/PRJNA219226). Other supporting data are included as additional files.

\section{Additional files}

\begin{abstract}
Additional file 1: Figure illustrating the change in soil moisture content (\%) during the drought experiment. The vertical red lines represent key time points in the course of the experiment. From left to right: DW0 - onset of drought; DW1 - mid-drought; DW2 - end of the drought treatment.
\end{abstract}

Additional file 2: Analysis of variance (ANOVA) table for the trait data presented in Table 1C. The analysis was performed as a split-plot in time design. The data for glucose, fructose, myo-inositol, malate and pinitol were $\log _{10}$ transformed. The analysis was performed using Genstat $15^{\text {th }}$ edition (VSN International Ltd; http://www.vsni.co.uk).

Additional file 3: Annotation of the $\mathbf{4 5 1 8 1}$ red clover transcript tags. Excel file showing the annotation of the red clover transcript tags as well as a description of the GO terms.

Additional file 4: Differentially expressed transcript tags in the sensitive and tolerant pools. The file is separated into three sheets: sensitive, tolerant and control for respective pairwise comparisons. The sensitive and tolerant tabs show differential expression in the two pools in response to drought stress. The control tab shows differentially expressed transcript tags from pairwise comparison of tolerant and sensitive pool before drought stress. The table shows relevant statistics and functional description in addition to expression values.

Additional file 5: Transcript tags containing SNPs. The excel file shows the SNP polymorphism, their annotation, the position of the SNP in the transcript tag and read counts of each allele. 
Additional file 6: Red clover transcript tags with SSR motifs. The SSRs were identified according to the Perl MISA script (see Methods), and the file lists the characteristics of the SSRs.

Additional file 7: Primer design for amplification of SSRs. This file provides information about primer design for the amplification of 2139 of the 3127 SSR motifs identified.

Additional file 8: Primers for qRT-PCR experiment.

Additional file 9: Relevant parameters for the gas chromatography mass spectroscopy (GC-MS) analysis.

\section{Abbreviations}

BLAST: Basic local alignment search tool; bp: Base pair; DREB: Dehydration responsive element binding; LEA: Late embryogenesis abundant; NADP: Nicotinamide adenine dinucleoside phosphate; PSI \& PSII: Photosystem I \& II; qRT-PCR: Quantitative real time polymerase chain reaction; ROS: Reactive oxygen species; Rubisco: Ribulose bisphosphate carboxylase; TAIR: The Arabidopsis Information Resource.

\section{Competing interests}

The authors declare that they have no competing interests.

\section{Authors' contributions}

SAY conceived, designed and performed the experiment, most of the analysis, and wrote the paper. MTS and MJH carried out de novo assembly of the transcriptome, IC annotated the transcriptome and assisted with programming. ML helped design and carry out the drought experiment. GGA designed the method for metabolite analysis and carried out some of the metabolite analyses. TR advised on the de novo assembly and critically read the manuscript. MTA and GJ conceived and supervised the study. LS conceived and supervised the study, carried out some of the analyses and wrote the paper. All authors read and approved the final manuscript.

\section{Acknowledgements}

This work was funded by the Biotechnology and Biological Sciences Research Council through the Crop Science 2007 Initiative, and an Institute Strategic Programme Grant (IBERS/08/2). We wish to thank Rhys Kelly for technical assistance, and Ruth Sanderson for advice on the statistical analysis of the data presented in Table 1 and Additional file 2

\section{Author details}

'Institute of Biological, Environmental and Rural Sciences, Aberystwyth University, Gogerddan, Aberystwyth, Ceredigion SY23 3 EB, UK. ${ }^{2}$ Institute of Biological, Environmental and Rural Sciences, Aberystwyth University, Penglais, Aberystwyth, Ceredigion SY23 3FL, UK. ${ }^{3}$ Present address: School of Biological Sciences, University of Essex, Wivenhoe Park, Colchester, Essex CO4 3SQ, UK. Institute for Agricultural and Fisheries Research (ILVO), Plant Sciences Unit - Growth and Development, Caritasstraat 21, 9090 Melle, Belgium. ${ }^{5}$ Present address: International Institute of Tropical Agriculture (ITA), PMB 5320, Oyo Road, Ibadan, Nigeria.

Received: 29 November 2013 Accepted: 4 June 2014

Published: 9 June 2014

\section{References}

1. Taylor NL, Quesenberry KH: Red Clover Science. Dordrecht: Kluwer Academic Publishers; 1996

2. Abberton MT, Marshall AH: Progress in breeding perennial clovers for temperate agriculture. J Agric Sci 2005, 143:117-135.

3. Frame J, Charlton JFL, Laidlaw AS: Temperate Forage Legumes. Wallingford: CAB International; 1998.

4. Nyfeler D, Huguenin-Elie O, Suter M, Frossard E, Connolly J, Lüscher A Strong mixture effects among four species in fertilized agricultural grassland led to persistent and consistent transgressive overyielding. J Appl Ecol 2009, 46:683-691.

5. Taylor NL: A century of clover breeding developments in the United States. Crop Sci 2008, 48:1-13.

6. Thomashow MF: molecular basis of plant cold acclimation: insights gained from studying the CBF cold response pathway. Plant Physiol 2010, 154:571-577.
7. Thomashow MF: Plant Cold Acclimation: Freezing Tolerance Genes and Regulatory Mechanisms. Annu Rev Plant Physiol Plant Mol Biol 1999, 50:571-599

8. Thomashow MF: Role of Cold-Responsive Genes in Plant Freezing Tolerance. Plant Physiol 1998, 118:1-8.

9. Rizhsky L, Liang $H$, Mittler R: The combined effect of drought stress and heat shock on gene expression in tobacco. Plant Physiol 2002, 130:1143-1151.

10. Rasmussen S, Barah $P$, Suarez-Rodriguez MC, Bressendorff S, Friis $P$, Costantino $P$, Bones AM, Nielsen HB, Mundy J: Transcriptome responses to combinations of Stresses in Arabidopsis. Plant Physiol 2013, 161:1783-1794.

11. Peterson PR, Sheaffer CC, Hall MH: Drought effects on perennial forage legume yield and quality. Agron J 1992, 84:6.

12. Herrmann D, Boller B, Studer B, Widmer F, Kölliker R: Improving persistence in red clover: insights from QTL analysis and comparative phenotypic evaluation. Crop Sci 2008, 48:269-277.

13. Klimenko I, Razgulayeva N, Gau M, Okumura K, Nakaya A, Tabata S, Kozlov $\mathrm{N}$, Isobe S: Mapping candidate QTLs related to plant persistency in red clover. Theor Appl Genet 2010, 120:1253-1263.

14. Lenka SK, Katiyar A, Chinnusamy V, Bansal KC: Comparative analysis of drought-responsive transcriptome in Indica rice genotypes with contrasting drought tolerance. Plant Biotechnol J 2011, 9:315-327.

15. Aprile A, Mastrangelo A, De Leonardis A, Galiba G, Roncaglia E, Ferrari F, De Bellis L, Turchi L, Giuliano G, Cattivelli L: Transcriptional profiling in response to terminal drought stress reveals differential responses along the wheat genome. BMC Genomics 2009, 10:279.

16. Matsui A, Ishida J, Morosawa T, Mochizuki Y, Kaminuma E, Endo TA, Okamoto M, Nambara E, Nakajima M, Kawashima M, et al: Arabidopsis Transcriptome Analysis under Drought, Cold, High-Salinity and ABA Treatment Conditions using a Tiling Array. Plant Cell Physiol 2008, 49:1135-1149.

17. Shinozaki K, Yamaguchi-Shinozaki K: Gene networks involved in drought stress response and tolerance. J Exp Bot 2007, 58:221-227.

18. Chaves MM, Flexas J, Pinheiro C: Photosynthesis under drought and salt stress: regulation mechanisms from whole plant to cell. Ann Bot 2009, 103:551-560.

19. Chaves MM, Maroco JP, Pereira JS: Understanding plant responses to drought - from genes to the whole plant. Funct Plant Biol 2003, 30:239-264.

20. Schroeder Jl, Allen GJ, Hugouvieux V, Kwak JM, Waner D: Guard cell signal transduction. Annu Rev Plant Physiol Plant Mol Biol 2001, 52:627-658.

21. Agarwal PK, Jha B: Transcription factors in plants and ABA dependent and independent abiotic stress signalling. Biol Plant 2010, 54:201-212.

22. Mittler R, Vanderauwera S, Gollery M, Van Breusegem F: Reactive oxygen gene network of plants. Trends Plant Sci 2004, 9:490-498.

23. Seki M, Narusaka M, Abe H, Kasuga M, Yamaguchi-Shinozaki K, Carninci $P$, Hayashizaki Y, Shinozaki K: Monitoring the Expression Pattern of 1300 Arabidopsis Genes under Drought and Cold Stresses by Using a Full-Length cDNA Microarray. Plant Cell 2001, 13:61-72.

24. Seki M, Narusaka M, Ishida J, Nanjo T, Fujita M, Oono Y, Kamiya A, Nakajima M, Enju A, Sakurai T, Satou M, Akiyama K, Taji T, Yamaguchi-Shinozaki K, Carninci P, Kawai J, Hayashizaki Y, Shinozaki K: Monitoring the expression profiles of 7000 Arabidopsis genes under drought, cold and high-salinity stresses using a full-length cDNA microarray. Plant J 2002, 31:279-292.

25. Seki M, Umezawa T, Urano K, Shinozaki K: Regulatory metabolic networks in drought stress responses. Curr Opin Plant Biol 2007, 10:296-302.

26. Ashraf M, Foolad MR: Roles of glycine betaine and proline in improving plant abiotic stress resistance. Environ Exp Bot 2007, 59:206-216.

27. Garg R, Patel RK, Tyagi AK, Jain M: De Novo Assembly of Chickpea Transcriptome Using Short Reads for Gene Discovery and Marker Identification. DNA Res 2011, 18:53-63.

28. Yang SS, Tu Z, Cheung F, Xu W, Lamb J, Jung H-J, Vance C, Gronwald J: Using RNA-Seq for gene identification, polymorphism detection and transcript profiling in two alfalfa genotypes with divergent cell wall composition in stems. BMC Genomics 2011, 12:199.

29. Zenoni S, Ferrarini A, Giacomelli E, Xumerle L, Fasoli M, Malerba G, Bellin D, Pezzotti M, Delledonne M: Characterization of Transcriptional Complexity during Berry Development in Vitis vinifera Using RNA-Seq. Plant Physiol 2010, 152:1787-1795

30. Mizrachi E, Hefer CA, Ranik, Joubert F, Myburg AA: De novo assembled expressed gene catalogue of a fast growing Eucalyptus tree produced by Illumina mRNA-Seq. BMC Genomics 2010, 11:681.

31. Wu T, Qin Z, Zhou X, Feng Z, Du Y: Transcriptome profile analysis of floral sex determination in cucumber. J Plant Physiol 2010, 167:905-913. 
32. Wang L, Li P, Brutnell TP: Exploring plant transcriptomes using ultra high-throughput sequencing. Briefings Funct Genom 2010, 9:118-128.

33. Kircher M, Kelso: High-throughput DNA sequencing - concepts and limitations. Bioessays 2010, 32:524-536.

34. Morozova O, Marra MA: Applications of next-generation sequencing technologies in functional genomics. Genomics 2008, 92(5):255-264.

35. Shendure J, Ji H: Next-generation DNA sequencing. Nat Biotechnol 2008, 26:1135-1145.

36. Mortazavi A, Williams BA, McCue K, Schaeffer L, Wold B: Mapping and quantifying mammalian transcriptomes by RNA-Seq. Nat Meth 2008 , 5:621-628.

37. Chen S, Zhou R, Huang Y, Zhang M, Yang G, Zhong C, Shi S: Transcriptome sequencing of a highly salt tolerant mangrove species Sonneratia alba using Illumina platform. Mar Genome 2011, 4:129-136.

38. Wang Z, Fang B, Chen J, Zhang X, Luo Z, Huang L, Chen X, Li Y: De novo assembly and characterization of root transcriptome using Illumina paired-end sequencing and development of cSSR markers in sweetpotato (Ipomoea batatas). BMC Genomics 2010, 11:726

39. O'Rourke JA, Yang SA, Miller SS, Bucciarelli B, Liu J, Rydeen A, Bozsoki Z, Uhde-Stone C, Tu ZJ, Allan D, Gronwald JW, Vance CP: An RNA-Seq transcriptome analysis of orthophosphate-deficient white lupin reveals novel insights into phosphorus acclimation in plants. Plant Physiol 2013, 161:705-724.

40. Rabbani MA, Maruyama K, Abe H, Khan MA, Katsura K, Ito Y, Yoshiwara K, Seki M, Shinozaki K, Yamaguchi-Shinozaki K: Monitoring Expression Profiles of Rice Genes under Cold, Drought, and High-Salinity Stresses and Abscisic Acid Application Using cDNA Microarray and RNA Gel-Blot Analyses. Plant Physiol 2003, 133:1755-1767.

41. Torii KU: Leucine-Rich Repeat Receptor Kinases in Plants: Structure, Function, and Signal Transduction Pathways. 2004, 234

42. Kanai R, Edwards GE: The biochemistry of C4 photosynthesis. In C4 Plant Biology. Edited by Sage RF, Monson RK. San Diego: Academic; 1999:49-87.

43. Hatch MD: C4 photosynthesis: A historical perspective. In C4 Plant Biology. Edited by Sage RF, Monson RK. San Diego: Academic; 1999:17-46.

44. Sato S, Isobe S, Asamizu E, Ohmido N, Kataoka R, Nakamura Y, Kaneko T, Sakurai N, Okumura K, Klimenko I, Sasamoto S, Wada T, Watanabe A, Kohara M, Fujishiro T, Tabata S: Comprehensive Structural Analysis of the Genome of Red Clover (Trifolium pratense L.). DNA Res 2005, 12:301-364.

45. Auer PL, Doerge RW: Statistical Design and Analysis of RNA Sequencing Data. Genetics 2010, 185:405-416.

46. Young ND, Debelle F, Oldroyd GED, Geurts R, Cannon SB, Udvardi MK, Benedito VA, Mayer KFX, Gouzy J, Schoof H, Van de Peer Y, Proost S, Cook DR, Meyers BC, Spannagl M, Cheung F, De Mita S, Krishnakumar V, Gundlach H, Zhou S, Mudge J, Bharti AK, Murray JD, Naoumkina MA, Rosen B, Silverstein KAT, Tang H, Rombauts S, Zhao PX, Zhou P, et al: The Medicago genome provides insight into the evolution of rhizobial symbioses. Nature 2011, 480:520-524.

47. Schmutz J, Cannon SB, Schlueter J, Ma J, Mitros T, Nelson W, Hyten DL, Song Q, Thelen JJ, Cheng J, Xu D, Hellsten U, May GD, Yu Y, Sakurai T, Umezawa T, Bhattacharyya MK, Sandhu D, Valliyodan B, Lindquist E, Peto M, Grant D, Shu S, Goodstein D, Barrie K, Futrell-Griggs M, Abernathy B, Du J, Tian Z, Zhu L, et al: Genome sequence of the palaeopolyploid soybean. Nature 2010, 463:178-183.

48. Swarbreck D, Wilks C, Lamesch P, Berardini TZ, Garcia-Hernandez M, Foerster H, Li D, Meyer T, Muller R, Ploetz L, Radenbaugh A, Singh S, Swing V, Tissier C, Zhang P, Huala E: The Arabidopsis Information Resource (TAIR): gene structure and function annotation. Nucl Acids Res 2008, 36(suppl 1):D1009-D1014.

49. Guo P, Baum M, Grando S, Ceccarelli S, Bai G, Li R, von Korff M, Varshney RK, Graner A, Valkoun J: Differentially expressed genes between droughttolerant and drought-sensitive barley genotypes in response to drought stress during the reproductive stage. J Exp Bot 2009, 60:3531-3544.

50. Rivero RM, Kojima M, Gepstein A, Sakakibara H, Mittler R, Gepstein S, Blumwald E: Delayed leaf senescence induces extreme drought tolerance in a flowering plant. Proc Natl Acad Sci U S A 2007, 104:19631-19636.

51. Flexas J, Medrano H: Drought-inhibition of photosynthesis in C-3 plants: Stomatal and non-stomatal limitations revisited. Ann Bot 2002, 89:183-189.

52. Vernon DM, Bohnert HJ: A novel methyl transferase induced by osmotic stress in the facultative halophyte Mesembryanthemum crystallinum. EMBO J 1992, 11:2077-2085.
53. Minchin FR, Minguez MI, Sheehy JE, Witty JF, Skøt L: Relationships between nitrate and oxygen supply in symbiotic nitrogen fixation by white clover. J Exp Bot 1986, 37:1103-1113.

54. Skøt L, Egsgaard H: Identification of ononitol and O-methyl-scyllo-inositol in pea root nodules. Planta 1984, 161:32-36.

55. Ford CW: Accumulation of low molecular weight solutes in water-stressed tropical legumes. Phytochemistry 1984, 23:1007-1015.

56. Herrmann D, Boller B, Studer B, Widmer F, Kölliker R: QTL analysis of seed yield components in red clover (Trifolium pratense L.). Theor Appl Genet 2006, 112:536-545

57. Smart RE, Bingham GE: Rapid Estimates of Relative Water Content. Plant Physiol $1974,53: 258-260$.

58. Zerbino DR, Birney E: Velvet: Algorithms for de novo short read assembly using de Bruijn graphs. Genome Res 2008, 18:821-829.

59. Baggerly KA, Deng L, Morris JS, Aldaz CM: Differential expression in SAGE: accounting for normal between-library variation. Bioinformatics 2003 19:1477-1483.

60. Apweiler R, Bairoch A, Wu CH, Barker WC, Boeckmann B, Ferro S, Gasteiger E, Huang H, Lopez R, Magrane M, Martin MJ, Natale DA, O'Donovan C, Redaschi N, Yeh LL: UniProt: the Universal Protein knowledgebase. Nucl Acids Res 2004, 32(suppl 1):D115-D119.

61. Consortium TU: Update on activities at the Universal Protein Resource (UniProt) in 2013. Nucl Acids Res 2013, 41(D1):D43-D47

62. Shannon P, Markiel A, Ozier O, Baliga NS, Wang JT, Ramage D, Amin N, Schwikowski B, Ideker T: Cytoscape: A Software Environment for Integrated Models of Biomolecular Interaction Networks. Genome Res 2003, 13:2498-2504.

63. Pfaffl MW, Horgan GW, Dempfle L: Relative expression software tool (RESTC) for group-wise comparison and statistical analysis of relative expression results in real-time PCR. Nucl Acids Res 2002, 30:e36.

64. Pfaffl MW: A new mathematical model for relative quantification in real-time RT-PCR. Nucl Acids Res 2001, 29:e45.

65. You F, Huo N, Gu Y, Luo M-c, Ma Y, Hane D, Lazo G, Dvorak J, Anderson O: BatchPrimer3: A high throughput web application for PCR and sequencing primer design. BMC Bioinform 2008, 9:253.

66. Parveen I, Moorby JM, Fraser MD, Allison GG, Kopka J: Application of gas chromatography - mass spectrometry metabolite profiling techniques to the analysis of heathland plant diets of sheep. J Agric Food Chem 2007, 55:1129-1138.

doi:10.1186/1471-2164-15-453

Cite this article as: Yates et al:: De novo assembly of red clover transcriptome based on RNA-Seq data provides insight into drought response, gene discovery and marker identification. BMC Genomics 2014 15:453

\section{Submit your next manuscript to BioMed Central and take full advantage of:}

- Convenient online submission

- Thorough peer review

- No space constraints or color figure charges

- Immediate publication on acceptance

- Inclusion in PubMed, CAS, Scopus and Google Scholar

- Research which is freely available for redistribution 